University of Nebraska - Lincoln

DigitalCommons@University of Nebraska - Lincoln

Reduced genomic potential for secreted plant cell-wall-degrading enzymes in the ectomycorrhizal fungus Amanita bisporigera, based on the secretome of Trichoderma reesei

\author{
Subashini Nagendran \\ DOE Plant Research Laboratory, East Lansing, MI \\ Heather E. Hallen-Adams \\ University of Nebraska-Lincoln, hhallen-adams2@unl.edu \\ Janet M. Paper \\ DOE Plant Research Laboratory, East Lansing, MI \\ Nighat Aslam \\ DOE Plant Research Laboratory, East Lansing, MI \\ Jonathan D. Walton \\ DOE Plant Research Lab, East Lansing, MI, walton@msu.edu
}

Follow this and additional works at: https://digitalcommons.unl.edu/gfihallenadams

Part of the Medical Sciences Commons

Nagendran, Subashini; Hallen-Adams, Heather E.; Paper, Janet M.; Aslam, Nighat; and Walton, Jonathan D., "Reduced genomic potential for secreted plant cell-wall-degrading enzymes in the ectomycorrhizal fungus Amanita bisporigera, based on the secretome of Trichoderma reesei" (2009). Dr. Heather HallenAdams Publications. 2.

https://digitalcommons.unl.edu/gfihallenadams/2

This Article is brought to you for free and open access by the Gut Function Initiative at DigitalCommons@University of Nebraska - Lincoln. It has been accepted for inclusion in Dr. Heather Hallen-Adams Publications by an authorized administrator of DigitalCommons@University of Nebraska - Lincoln. 


\title{
Reduced genomic potential for secreted plant cell-wall-degrading enzymes in the ectomycorrhizal fungus Amanita bisporigera, based on the secretome of Trichoderma reesei
}

\author{
Subashini Nagendran ${ }^{\mathrm{a}, \mathrm{b}}$, Heather E. Hallen-Adams ${ }^{\mathrm{a}}$, Janet M. Paper ${ }^{\mathrm{a}}$, Nighat Aslam ${ }^{\mathrm{a}, \mathrm{b}}$, \\ Jonathan D. Walton ${ }^{\mathrm{a}, \mathrm{b}, *}$ \\ ${ }^{a}$ DOE Plant Research Laboratory, Michigan State University, E. Lansing MI 48824, USA \\ ${ }^{\mathrm{b}}$ Great Lakes Bioenergy Research Center, Michigan State University, E. Lansing MI 48824, USA
}

\section{A R T I C L E I N F O}

\section{Article history:}

Received 13 December 2008

Accepted 6 February 2009

Available online 13 February 2009

\section{Keywords:}

Proteomics

Cellulase

Xylanase

\begin{abstract}
A B S T R A C T
Based on the analysis of its genome sequence, the ectomycorrhizal (ECM) basidiomycetous fungus Laccaria bicolor was shown to be lacking many of the major classes of secreted enzymes that depolymerize plant cell wall polysaccharides. To test whether this is also a feature of other ECM fungi, we searched a survey genome database of Amanita bisporigera with the proteins found in the secretome of Trichoderma reesei (syn. Hypocrea jecorina), a biochemically well-characterized industrial fungus. Additional proteins were also used as queries to compensate for major groups of cell-wall-degrading enzymes lacking in the secretome of $T$. reesei and to substantiate conclusions drawn from the T. reesei collection. By MS/MS-based "shotgun" proteomics, 80 proteins were identified in culture filtrates of $T$. reesei strain RUTC30 grown on corn cell walls and in a commercial "cellulase" preparation, Spezyme CP. The two T. reesei enzyme preparations were qualitatively and quantitatively similar, the most striking difference being the lack of at least five major peptidases from the commercial enzyme mixture. Based on our analysis of $A$. bisporigera, this ECM fungus is deficient in many major classes of cell-wall-degrading enzymes, including both glycosyl hydrolases and carbohydrate esterases. By comparison, the genomes of the saprophytic basidiomycetes Coprinopsis cinerea and Galerina marginata (using a genome survey sequence approximately equivalent in depth to that of $A$. bisporigera) have, like $T$. reesei, a much more complete complement of cell-wall-degrading enzymes.
\end{abstract}

(c) 2009 Elsevier Inc. All rights reserved.

\section{Introduction}

The secretion of enzymes to degrade biological polymers is a defining feature of the Kingdom Mycota. Plant cell walls constitute the largest single source of available reduced carbon in terrestrial environments, and fungi secrete a large number and variety of enzymes that can act on the linkages found in plant cell walls, including cellulases, hemicellulases, pectinases, esterases, oxidoreductases, and proteases. Some filamentous fungi secrete more than two hundred glycosyl hydrolases alone (Cuomo et al., 2007; Dean et al., 2005).

Based on the analysis of the full genome sequence of Laccaria bicolor, Martin et al. (2008) concluded that this ectomycorrhizal (ECM) fungus is deficient in the capacity to produce extracellular enzymes active on plant cell wall polysaccharides, compared to ascomycetes and both saprophytic and pathogenic basidiomycetes.

\footnotetext{
* Corresponding author. Address: DOE Plant Research Lab, Michigan State University, E. Lansing MI 48824, USA. Fax: +1 5173539168.

E-mail address: walton@msu.edu (J.D. Walton).
}

This observation has potentially major implications for understanding ECM symbiotic interactions, because cell-wall-degrading enzymes are well-documented to play an important role in modulating the interactions between fungi and plants. Many fungal enzymes are directly or indirectly detrimental to plant cells. They can kill plant cells by weakening the essential cell wall, leading to reduced growth and ultimately death by osmotic shock, and can also trigger a number of defense responses such as phytoalexin biosynthesis, reactive oxygen species, callose deposition, and the hypersensitive response (Walton, 1994). Induction of defense responses in some cases is caused by the enzymes themselves and sometimes by the oligosaccharide products of their enzymatic action (Beliën et al., 2006; D'Ovidio et al., 2004). Plants respond in multiple ways to degradative enzymes such as pectinases and xylanases of both pathogens and saprophytes, and plants contain a number of proteins that inhibit microbial enzymes, including polygalacturonase, pectin lyase, xylanase, and pectin methylesterase (Enkerli et al., 1999; Lionetti et al., 2007). Whether an ECM fungus does or does not secrete enzymes (and other proteins) that interact with plant cell walls could therefore have a major impact on its ability to form a viable ECM symbiotic relationship. 
Of 12 families of glycosyl hydrolases active on plant cell wall polysaccharides, the genome of $L$. bicolor lacks nine (Martin et al., 2008). L. bicolor does have six members in family GH28, which contains all known fungal polygalacturonases (PGs). PGs are among the best-studied plant-cell-wall degradative enzymes. They induce defense responses via the release of elicitor-active oligogalacturonides and in some pathosystems contribute to virulence (D'Ovidio et al., 2004; Scott-Craig et al., 1998; ten Have et al., 1998). L. bicolor also has genes encoding enzymes in GH families 5 and 9, as well as members of carbohydrate esterase (CE) family 8 (Martin et al., 2008).

The results from studies on plant-active degradative enzymes in other ECM fungi are mixed. Colpaert and van Tichelin (1996) found that ECM fungi had no or limited ability to decompose beech leaf litter, and Hutchison (1990) found no cellulase or pectinase producers among 96 species of ECM fungi. On the other hand, Amanita regalis, Paxillus involutus, and Suillus bovinus produce cellulase activity (Maijala et al., 1991), and Thelephora terrestris and S. bovinus produce $\beta$-xylosidase and $\beta$-glucosidase activities (Colpaert and van Laere, 1996). Pisolithus tinctorius has endoglucanase and exoglucanase activities (Cao and Crawford, 1993), and Tricholoma matsutake has glucosidase, cellulase, xylanase, and amylase activities (Kusuda et al., 2008; Terashita et al., 1995). However, apparently none of these reports of enzyme activities in ECM fungi have been confirmed by enzyme purification or genetic analysis. It therefore remains an open question whether a general deficiency of such enzymes is a general attribute of ECM fungi, or whether it might be peculiar to L. bicolor. Rather than being a general property of ECM fungi, a deficiency in enzymes might instead be negatively correlated with the capacity to grow saprophytically (at least facultatively), or positively with the ability to form a symbiotic association with a particular host or hosts, or with ecological biome (Read and Perez-Moreno, 2003).

We recently sequenced $84.3 \mathrm{Mb}$ (final assembled size) of genomic DNA of Amanita bisporigera (constituting $\sim 2 \times$ coverage, assuming a genome size of $\sim 40 \mathrm{Mb}$ ) (Hallen et al., 2007) and $46.1 \mathrm{Mb}$ of Galerina marginata $(\sim 1.2 \times)$ (unpublished results). Our original interest in both of these fungi is their ability to make cyclic peptide toxins such as amatoxins and phallotoxins (Hallen et al., 2007), but the availability of these genome survey sequences are a useful resource for other purposes as well. In the present case, we have used these survey genome sequences to address the question of whether A. bisporigera, an ECM fungus, has, like L. bicolor, a reduction in its number of secreted cell-wall-degrading enzymes.

A. bisporigera is an obligate ectomycorrhizal symbiont - notably of oaks and pines - and is native to North and Central America. Some but not all specimens possess two-spored basidia, and the current consensus is that North American specimens called by the European name $A$. virosa are really four-spored $A$. bisporigera. G. marginata is a saprophytic (wood-rotting) mushroom found circumboreally (Gulden et al., 2001). L. bicolor and Coprinopsis cinerea (which is sequenced and used in the present study) grow well and readily form fruiting bodies in culture (Davis and Jong, 1976), whereas $A$. bisporigera and $G$. marginata grow slowly in culture. On rich nutrient agar, $A$. bisporigera grows $\sim 1 \mathrm{~cm} /$ month, and $G$. marginata $\sim 3 \mathrm{~cm} /$ month (Zhang et al., 2005; unpublished results from this lab).

The goal of the present investigation was to test whether A. bisporigera more closely resembles $L$. bicolor in having a reduced genomic capacity to synthesize and secrete enzymes that break linkages found in plant cell wall polysaccharides and other polymers, or whether $A$. bisporigera more closely resembles most other fungi in making a large number of such enzymes. In order to address this question, it is first necessary to define a suitable set of enzymes/genes to use as queries. For the analysis of $L$. bicolor, Martin et al. (2008) relied on the CAZy "Carbohydrate-Active EnZYme" database, (Cantarel et al., in press; Henrissat and Davies, 1997), which contains $>140$ families of enzymes that degrade linkages found in natural polysaccharides. However, many of these families, as well as some specific members within each family, are known or predicted to be involved in processes other than extracellular degradation of the wall components of higher plants, such as endogenous remodeling of fungal walls, modification of glycoproteins, degradation of small saccharides such as sucrose and trehalose, degradation of storage polysaccharides such as starch and glycogen, and degradation of insect and animal-derived polymers. In addition, many of these classified genes/enzymes are biochemically uncharacterized (as are the vast majority of GenBank entries). As an alternative, but also complementary, approach, we have used as query proteins a set of relevant proteins, namely the secreted proteins of the ascomycete Trichoderma reesei (Hypocrea jecorina).

$T$. reesei is a well-studied degrader of lignocellulose and its enzymes are used industrially on a large scale (Merino and Cherry, 2007). It secretes a large quantity and diversity of enzymes that are active on linkages found in plant cell polysaccharides (Stricker et al., 2008). Many of the extracellular enzymes of $T$. reesei have been biochemically characterized and therefore their use to search for orthologs in other organisms provides more robust information and avoids potentially misleading results associated with using proteins of only hypothetical function or function deduced by amino acid similarity. Many of the classes of cell-wall-degrading enzymes of $T$. reesei are widespread in the fungal kingdom and therefore they constitute an archetypal set of proteins to use as queries against other fungi.

Compared to degradative enzymes secreted by ascomycetes, those of basidiomycetes are collectively less well characterized. Nonetheless, it has been shown that basidiomycetes secrete many of the same enzyme activities and classes of carbohydrate-active enzymes as ascomycetes, such as cellulases, pectinases, and xylanases (Ding et al., 2006; Baldrian and Gabriel, 2003). Therefore, it appears justified to use the $T$. reesei secretome as a starting point to explore the secreted, degradative potential of another fungus such as $A$. bisporigera.

\section{Materials and methods}

\subsection{Fungal growth and protein production}

T. reesei (Hypocrea jecorina) was grown in medium containing $4 \mathrm{mM} \mathrm{Ca}\left(\mathrm{NO}_{3}\right)_{2} \cdot 4 \mathrm{H}_{2} \mathrm{O}, 1 \mathrm{mM} \mathrm{K} \mathrm{HPO}_{4}, 1 \mathrm{mM} \mathrm{MgSO}{ }_{4} \cdot 7 \mathrm{H}_{2} \mathrm{O}$, and $2.5 \mathrm{mM} \mathrm{NaCl}$, supplemented with $1 \%(\mathrm{w} / \mathrm{v})$ corn stover pretreated by ammonia fiber explosion (AFEX) (Teymouri et al., 2005). Each 1-l flask contained $125 \mathrm{ml}$ medium. The flasks were inoculated with five $1-\mathrm{cm}^{2}$ agar plugs of actively growing $T$. reesei RUTC30 (NRRL 11460; Agricultural Research Service Culture Collection, Peoria, Illinois) growing on V8-juice agar. The cultures were maintained without shaking at $21^{\circ} \mathrm{C}$ for 14 days. Culture filtrates were concentrated 100 -fold by rotary evaporation under vacuum at $35^{\circ} \mathrm{C}$ and lyophilized to dryness, then redissolved in $5 \mathrm{ml}$ water and buffer-exchanged into $0.1 \mathrm{M}$ citrate buffer ( $\mathrm{pH} 4.8$ ). Spezyme CP was obtained from Genencor (Batch \# 301-05330-206). Protein concentration was determined by the BCA method (Pierce, Rockford, Illinois), using bovine immunoglobulin as standard (Smith et al., 1985).

\subsection{Proteomics}

For proteomics analysis, the protein preparations $(200 \mu \mathrm{g}$ protein each) were fractionated in two lanes on a BioRad (Richmond, CA) 4-20\% gradient SDS polyacrylamide gel. The gel lanes were each divided into 10 slices and each slice was individually processed. The proteins were alkylated with iodoacetamide and di- 
gested with sequencing-grade modified porcine trypsin (Promega). The digested peptides were injected with a ThermoElectron MicroAutosampler onto an Agilent Zorbax 300 SB-C18 $5 \times 0.3 \mathrm{~mm}$ peptide trap column and desalted for $10 \mathrm{~min}$. The bound peptides were then eluted onto a $10 \mathrm{~cm} \times 75 \mu \mathrm{m}$ New Objectives Picofrit column packed with Microm Magic C18 AQ and eluted over $120 \mathrm{~min}$ with a gradient of $5 \%$ B to $50 \%$ B in $75 \mathrm{~min}$, then $50 \%$ B to $90 \%$ B from 75 min to 79 min using a ThemoElectron Surveyor high-pressure liquid chromatograph. Buffer A was $99.9 \%$ water $+0.1 \%$ formic acid, and buffer $B$ was $99.9 \%$ acetonitrile $+0.1 \%$ formic acid. The peptides were eluted into a ThermoElectron LTQ/FT mass spectrometer at a flow rate of $250 \mathrm{nl} / \mathrm{min}$. Survey scans were taken at a resolution of 100,000 and the top ten ions in each survey scan were subjected to automatic low-energy collision-induced dissociation (CID) in the linear trap (LTQ). Fragment tolerance was $0.80 \mathrm{Da}$ (monoisotopic), and the parent was tolerance $200 \mathrm{ppm}$ (monoisotopic). Complete and partial residue modifications were allowed as well as point mutations and two missed cleavage sites.

Scaffold version 01_07_00 (Proteome Software, Portland, Oregon) was used to probabilistically validate protein identifications in the T. reesei proteome (v. 2.0, DOE Joint Genome Institute) using the X!Tandem and ProteinProphet computer algorithms (Craig and Beavis, 2003; Nesvizhskii et al., 2003). Minimum criteria for positive identification were at least two peptides and $>95 \%$ probability in at least one of the two samples as determined by Scaffold.

\subsection{Genome sequencing of A. bisporigera and G. marginata}

The genome of $A$. bisporigera was sequenced randomly by a combination of Sanger and first and second-generation 454 pyrosequencing. (First-generation 454 sequencing produced read lengths of $\sim 110 \mathrm{bp}$ and the second generation FLX machine produces read lengths of $\sim 250 \mathrm{bp}$ ). The resulting sequences were assembled using the 454 de novo assembler Newbler and put into a BLAST searchable database (Hallen et al., 2007). The assembled database of $A$. bisporigera contains $84.2 \mathrm{Mb}$ in 620,627 contigs. $G$. marginata was sequenced using the 454 FLX for a total of 198,877 contigs in $46.1 \mathrm{Mb}$.

\subsection{Database searching}

Each $T$. reesei protein was used as query in TBLASTN against the L. bicolor database (v. 1, DOE Joint Genome Institute, http:// genome.jgi-psf.org/euk_cur1.html), the A. bisporigera and G. marginata databases (http://genomics.msu.edu/Amanita/blast/blast.html), and the $C$. cinerea (Coprinus cinereus) database at the Broad Institute (http://www.broad.mit.edu/annotation/genome/coprinus_cinereus.2/Blast.html). For all searches, the word size was three and the matrix was BLOSUM62. For L. bicolor and C. cinerea, the databases used were "Best Models (transcripts)" or "transcripts", respectively. Expect cutoff scores greater than $1.00 \mathrm{E}-05$ were tabulated as "No hit". Hits to Carbohydrate Binding Modules (CBM) alone were analyzed separately.

Because the genome of $A$. bisporigera is not complete, some genes may be absent or underrepresented. To control for this, we did two experiments. One was to search all four fungi with a representative group of housekeeping proteins. The second was to search the genome survey sequences of the saprophytic mushroom G. marginata, whose incompleteness is comparable to that of A. bisporigera. Most of the A. bisporigera and G. marginata database contigs are shorter than full-length transcripts, resulting in the best hit scores being typically less significant than those obtained from searching the $C$. cinerea or $L$. bicolor genomes. For A. bisporigera and G. marginata, the best hits were saved no matter how poor their scores were. All hit sequences from A. bisporigera and G. marginata were re-checked using BLASTX against the GenBank NR database. In every case in which the best expect score was $<1.00 \mathrm{E}-03$, the $A$. bisporigera or G. marginata sequence identified at least one fungal gene annotated as related to the function of the original query protein. In every case in which the best score was $>1.00 \mathrm{E}-03$, the best hit by BLASTX was to a clearly unrelated gene.

\section{Results}

\subsection{The secretome of $T$. reesei}

A total of 82 proteins were identified at high reliability in the secretome of either $T$. reesei RUTC30 grown on maize cell walls or Spezyme CP. For subsequent analysis, proteins that could be identified as housekeeping proteins (e.g., ferredoxin, topoisomerase, aldolase, transcription factor, ubiquitin, etc.) were discarded, reducing the number to 60 (Table 1 ). Fifty-one of these were found in culture filtrates of RUTC30 and 41 in Spezyme CP. A number of proteins near the bottom of the list (i.e., those of lowest abundance based on spectral counts) (Table 1) also appear to be only in one or the other preparation, but some of these qualitative differences might be spurious, i.e., due to the greater technical difficulty of detecting lower abundance proteins. The mass spectrometry data were also analyzed using the entire GenBank NR protein database instead of only the $T$. reesei proteome. No evidence for proteins from other organisms was found in Spezyme $\mathrm{CP}$, that is, this commercial cellulase preparation is derived from $T$. reesei alone.

Thirty-one of the identified proteins were glycosyl hydrolases, ten were peptidases, six were esterases, two were nucleases, one was an oxidoreductase, and ten were non-enzymatic or unknown (Table 1). Altogether, 21 CAZy Glycosyl Hydrolase (GH) families, 10 peptidase families, and three carbohydrate esterase (CE) families are represented in the $T$. reesei secretome (Table 1 ). Based on our results, $T$. reesei does not secrete any significant quantity of any pectin lyase (PL). BlastP searching of the T. reesei database supported this conclusion; representatives of PL1, PL3, and PL4 (see Table 2) did not find any orthologous proteins in $T$. reesei at an expect score of $<1.00 \mathrm{E}-5$.

The proteins in Table 1 are listed in order of descending abundance based on total spectral counts in RUTC30. The number of spectral counts (i.e., the number of times the mass spectrometer detected a peptide corresponding to a particular protein) and the percent of the full-length protein sequence that was covered by the peptides (percent amino acid coverage) are shown. Spectral counts and sequence coverage are strongly correlated with protein abundance, although exceptions due to, e.g., heavy glycosylation, can occur (Chen et al., 2005). Most proteins have approximately the same relative abundance in Spezyme CP and RUTC30 grown on corn stover (Fig. 1). Xylanase 3, $\beta$-xylosidase, and an unknown predicted glycosyl hydrolase (GH30A) appear to be significantly more abundant in one or the other. Unknown protein 70840 was present at $>95 \%$ probability in RUTC30 but $80-94 \%$ probability in Spezyme CP. Of the qualitative differences among the more abundant proteins, the most striking difference is the absence in Spezyme CP of at least six extracellular proteases (proteins 123234, 73897, 107142, 110220, 70800, and 22459) (Fig. 1, Table 1). The presence of all of these in RUTC30 is strongly supported by percent coverage and spectral counts (Table 1 ). A probable explanation for this observation is that the strain of $T$. reesei used to make Spezyme $\mathrm{CP}$ has had its major protease genes mutated or down-regulated. Intentional genetic modification might also explain the absence of chitinase (80833) from Spezyme CP (Fig. 1).

$\beta$-Galactosidase was found in Spezyme CP but not in RUTC30. A plausible explanation for this is the use of lactose, the substrate of $\beta$-galactosidase, for induction of cellulase gene expression in 
Table 1

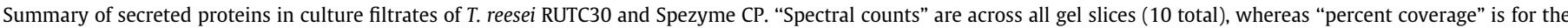
best slice. Names indicate known or predicted function; "glycosyl hydrolase" is a general prediction based on GenBank/pfam conserved domains or annotation of orthologs.

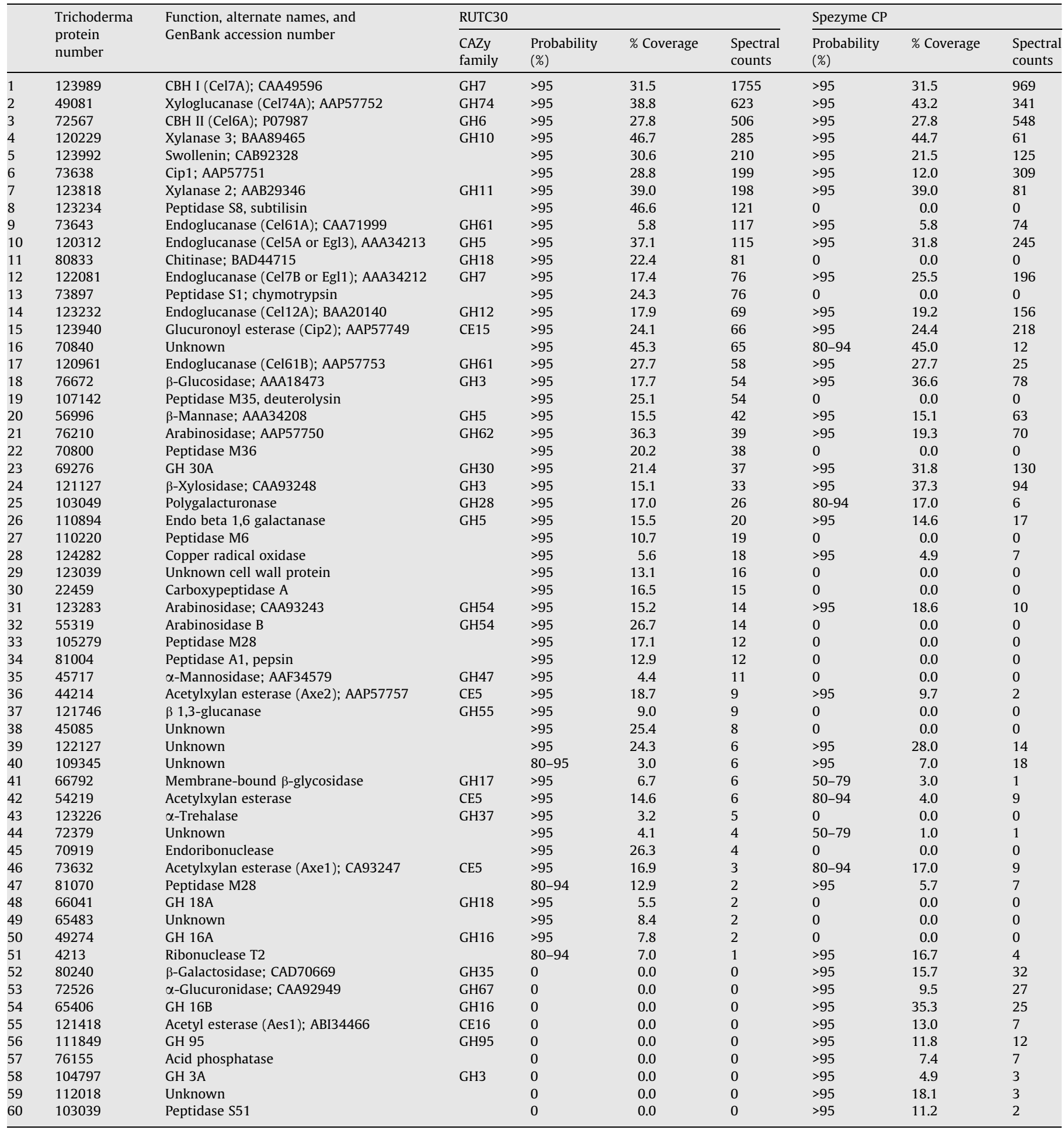

commercial fermentations (Fekete et al., 2008). Corn stover contains little if any $\beta$-linked galactose.

T. reesei is known to lack significant capacity to degrade lignin, which process is catalyzed by oxidative enzymes in white rot fungi such as Phanerochaete chrysosporium (Kersten and Cullen, 2007). Consistent with this, only a single putative oxidoreductase (124282) was detected in the secretome of $T$. reesei (Table 1).

\subsection{Analysis of plant-wall-degrading enzymes in two saprophytic and two ECM basidiomycetes}

Two approaches were used to validate the use of the incomplete genome of $A$. bisporigera for analyzing its complement of secreted degradative enzymes. First, all searches were also performed against the $G$. marginata partial genome database. Because the sequences of this basidiomycete fungus were also generated by 454 
Table 2

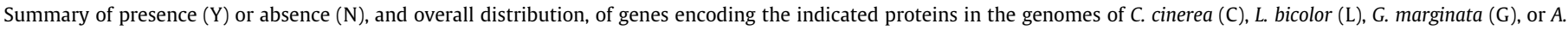
bisporigera (A).

\begin{tabular}{|c|c|c|c|c|c|c|c|c|}
\hline & $\begin{array}{l}\text { Trichoderma reesei } \\
\text { protein number }\end{array}$ & Name; known or predicted function & $\begin{array}{l}\text { CaZy } \\
\text { family }\end{array}$ & $\begin{array}{l}\text { Coprinopsis } \\
\text { cinerea }\end{array}$ & $\begin{array}{l}\text { Laccaria } \\
\text { bicolor }\end{array}$ & $\begin{array}{l}\text { Galerina } \\
\text { marginata }\end{array}$ & $\begin{array}{l}\text { Amanita } \\
\text { bisporigera }\end{array}$ & Distribution \\
\hline 1 & 123989 & Cel7A (CBH I) & GH7 & $\mathrm{Y}$ & $\mathrm{N}$ & $\mathrm{Y}$ & $\mathrm{N}$ & CG \\
\hline 2 & 49081 & Cel74A (xyloglucanase) & GH74 & $\mathrm{Y}$ & $\mathrm{N}$ & $\mathrm{Y}$ & $\mathrm{N}$ & CG \\
\hline 3 & 72567 & Cel6A (CBH II) & GH6 & $\mathrm{Y}$ & $\mathrm{N}$ & $\mathrm{Y}$ & $\mathrm{N}$ & CG \\
\hline 4 & 120229 & Xylanase 3 & GH10 & $\mathrm{Y}$ & $\mathrm{N}$ & $\mathrm{Y}$ & $\mathrm{N}$ & CG \\
\hline 5 & 123992 & Swollenin & & $\mathrm{N}$ & $\mathrm{N}$ & $\mathrm{N}$ & $\mathrm{N}$ & None \\
\hline 6 & 73638 & Cip1 & & $\mathrm{N}$ & $\mathrm{N}$ & $\mathrm{N}$ & $\mathrm{N}$ & None \\
\hline 7 & 123818 & Xylanase 2 & GH11 & $\mathrm{Y}$ & $\mathrm{N}$ & $\mathrm{Y}$ & $\mathrm{N}$ & CG \\
\hline 8 & 123234 & Peptidase S8 & & $\mathrm{Y}$ & $\mathrm{Y}$ & $\mathrm{Y}$ & $\mathrm{Y}$ & All \\
\hline 9 & 73643 & Cel61A & GH61 & $\mathrm{Y}$ & $\mathrm{Y}$ & $\mathrm{Y}$ & $\mathrm{Y}$ & All \\
\hline 10 & 120312 & Cel5A & GH5 & $\mathrm{Y}$ & $\mathrm{Y}$ & $\mathrm{Y}$ & $\mathrm{N}$ & CLG \\
\hline 11 & 80833 & Chitinase & GH18 & $\mathrm{Y}$ & $\mathrm{Y}$ & $\mathrm{Y}$ & $\mathrm{Y}$ & All \\
\hline 12 & 122081 & Cel7B & GH7 & $\mathrm{Y}$ & $\mathrm{N}$ & $\mathrm{Y}$ & $\mathrm{N}$ & CG \\
\hline 13 & 73897 & Peptidase S1 & & $\mathrm{N}$ & $\mathrm{N}$ & $\mathrm{N}$ & $\mathrm{N}$ & None \\
\hline 14 & 123232 & Cel12A & GH12 & $\mathrm{Y}$ & $\mathrm{N}$ & $\mathrm{Y}$ & $\mathrm{N}$ & CG \\
\hline 15 & 123940 & Cip2 & CE15 & $\mathrm{Y}$ & $\mathrm{N}$ & $\mathrm{Y}$ & $\mathrm{N}$ & CG \\
\hline 17 & 120961 & Cel61B & GH61 & $\mathrm{Y}$ & $\mathrm{Y}$ & $\mathrm{Y}$ & $\mathrm{Y}$ & All \\
\hline 18 & 76672 & $\beta$-Glucosidase & GH3 & $\mathrm{Y}$ & $\mathrm{Y}$ & $\mathrm{Y}$ & $\mathrm{Y}$ & All \\
\hline 19 & 107142 & Peptidase M35 & & $\mathrm{Y}$ & $\mathrm{N}$ & $\mathrm{N}$ & $\mathrm{N}$ & $\mathrm{C}$ \\
\hline 20 & 56996 & $\beta$-Mannanase & GH5 & $\mathrm{Y}$ & $\mathrm{Y}$ & $\mathrm{Y}$ & $\mathrm{Y}$ & All \\
\hline 21 & 76210 & Arabinosidase & GH62 & $\mathrm{Y}$ & $\mathrm{N}$ & $\mathrm{Y}$ & $\mathrm{N}$ & CG \\
\hline 22 & 70800 & Peptidase M36 & & $\mathrm{Y}$ & $\mathrm{Y}$ & $\mathrm{Y}$ & $\mathrm{Y}$ & All \\
\hline 23 & 69276 & GH 30A & GH30 & $\mathrm{Y}$ & $\mathrm{N}$ & $\mathrm{N}$ & $\mathrm{N}$ & $\mathrm{C}$ \\
\hline 24 & 121127 & $\beta$-Xylosidase & GH3 & $\mathrm{Y}$ & $\mathrm{N}$ & $\mathrm{Y}$ & $\mathrm{N}$ & CG \\
\hline 25 & 103049 & Polygalacturonase & GH28 & $\mathrm{Y}$ & $\mathrm{Y}$ & $\mathrm{Y}$ & $\mathrm{N}$ & CLG \\
\hline 26 & 110894 & Endo-galactanase & GH5 & $\mathrm{N}$ & $\mathrm{N}$ & $\mathrm{Y}$ & $\mathrm{N}$ & G \\
\hline 27 & 110220 & Peptidase M6 & & $\mathrm{N}$ & $\mathrm{N}$ & $\mathrm{N}$ & $\mathrm{N}$ & None \\
\hline 28 & 124282 & Copper radical oxidase & & $\mathrm{Y}$ & $\mathrm{Y}$ & $\mathrm{Y}$ & $\mathrm{Y}$ & All \\
\hline 30 & 22459 & Carboxypeptidase A & & $\mathrm{N}$ & $\mathrm{N}$ & $\mathrm{N}$ & $\mathrm{N}$ & None \\
\hline 31 & 123283 & Arabinosidase & GH54 & $\mathrm{N}$ & $\mathrm{N}$ & $\mathrm{Y}$ & $\mathrm{N}$ & G \\
\hline 32 & 55319 & Arabinosidase B & GH54 & $\mathrm{N}$ & $\mathrm{N}$ & $\mathrm{Y}$ & $\mathrm{N}$ & G \\
\hline 33 & 105279 & Peptidase M28 & & $\mathrm{Y}$ & $\mathrm{Y}$ & $\mathrm{Y}$ & $\mathrm{N}$ & CLG \\
\hline 34 & 81004 & Peptidase A1 & & $\mathrm{Y}$ & $\mathrm{Y}$ & $\mathrm{N}$ & $\mathrm{Y}$ & CLA \\
\hline 35 & 45717 & $\alpha$-Mannosidase & GH47 & $\mathrm{Y}$ & $\mathrm{Y}$ & $\mathrm{Y}$ & $\mathrm{Y}$ & All \\
\hline 36 & 44214 & Acetylxylan esterase (Axe2) & CE5 & $\mathrm{Y}$ & $\mathrm{Y}$ & $\mathrm{Y}$ & $\mathrm{N}$ & CLG \\
\hline 37 & 121746 & $\beta$ 1,3-glucanase & GH55 & $\mathrm{Y}$ & $\mathrm{Y}$ & $\mathrm{Y}$ & $\mathrm{Y}$ & All \\
\hline 42 & 54219 & Acetylxylan esterase & CE5 & $\mathrm{Y}$ & $\mathrm{Y}$ & $\mathrm{Y}$ & $\mathrm{N}$ & CLG \\
\hline 43 & 123226 & $\alpha$-Trehalase & GH37 & $\mathrm{Y}$ & $\mathrm{Y}$ & $\mathrm{Y}$ & $\mathrm{Y}$ & All \\
\hline 45 & 70919 & Endoribonuclease & & $\mathrm{N}$ & $\mathrm{N}$ & $\mathrm{N}$ & $\mathrm{Y}$ & A \\
\hline 46 & 73632 & Acetylxylan esterase (Axe1) & CE5 & $\mathrm{Y}$ & $\mathrm{Y}$ & $\mathrm{Y}$ & $\mathrm{N}$ & CLG \\
\hline 47 & 81070 & Peptidase M28 & & $\mathrm{Y}$ & $\mathrm{N}$ & $\mathrm{Y}$ & $\mathrm{N}$ & CG \\
\hline 48 & 65162 & GH 18A (chitinase) & GH18 & $\mathrm{Y}$ & $\mathrm{Y}$ & $\mathrm{Y}$ & $\mathrm{Y}$ & All \\
\hline 50 & 49274 & GH $16 A$ & GH16 & $\mathrm{Y}$ & $\mathrm{Y}$ & $\mathrm{Y}$ & $\mathrm{Y}$ & All \\
\hline 51 & 4213 & Ribonuclease T2 & & $\mathrm{N}$ & $\mathrm{Y}$ & $\mathrm{Y}$ & $\mathrm{Y}$ & LGA \\
\hline 52 & 80240 & $\beta$-Galactosidase & GH35 & $\mathrm{N}$ & $\mathrm{Y}$ & $\mathrm{Y}$ & $\mathrm{Y}$ & LGA \\
\hline 53 & 75526 & $\alpha$-Glucuronidase & GH67 & $\mathrm{N}$ & $\mathrm{N}$ & $\mathrm{Y}$ & $\mathrm{Y}$ & GA \\
\hline 54 & 65406 & GH 16B & GH16 & $\mathrm{Y}$ & $\mathrm{Y}$ & $\mathrm{Y}$ & $\mathrm{N}$ & CLG \\
\hline 55 & 121418 & Acetyl esterase (Aes1) & CE16 & $\mathrm{Y}$ & $\mathrm{N}$ & $\mathrm{Y}$ & $\mathrm{N}$ & CG \\
\hline 56 & 111894 & GH 95A & GH95 & $\mathrm{N}$ & $\mathrm{Y}$ & $\mathrm{Y}$ & $\mathrm{Y}$ & LGA \\
\hline 57 & 71092 & Acid phosphatase & & $\mathrm{N}$ & $\mathrm{Y}$ & $\mathrm{Y}$ & $\mathrm{Y}$ & LGA \\
\hline 58 & 104797 & $\mathrm{GH} 3 \mathrm{~A}$ & GH3 & $\mathrm{Y}$ & $\mathrm{Y}$ & $\mathrm{Y}$ & $\mathrm{Y}$ & All \\
\hline \multirow[t]{2}{*}{60} & 103039 & Peptidase S51 & & $\mathrm{N}$ & $\mathrm{N}$ & $\mathrm{N}$ & $\mathrm{N}$ & None \\
\hline & \multicolumn{8}{|c|}{ Other genes: organism and accession number } \\
\hline 61 & Cochliobolus carbonum (AF095243) & $\beta$-Xylosidase (XYP1) & GH43 & $\mathrm{Y}$ & $\mathrm{N}$ & $\mathrm{Y}$ & $\mathrm{N}$ & CG \\
\hline 62 & C. carbonum (L48982) & Exo-polygalacturonase (PGX1) & GH28 & $\mathrm{Y}$ & $\mathrm{Y}$ & $\mathrm{Y}$ & $\mathrm{N}$ & CLG \\
\hline 63 & C. carbonum (M55979) & Endo-polygalacturonase (PGN1) & GH28 & $\mathrm{Y}$ & $\mathrm{Y}$ & Y & $\mathrm{N}$ & CLG \\
\hline 64 & T. reesei (CAA83846) & Endoglucanase V & GH45 & $\mathrm{N}$ & $\mathrm{N}$ & $\mathrm{Y}$ & $\mathrm{N}$ & G \\
\hline 65 & Aspergillus kawachii (BAB96815) & Arabinosidase & GH51 & $\mathrm{Y}$ & $\mathrm{N}$ & $\mathrm{Y}$ & $\mathrm{N}$ & CG \\
\hline 66 & Aspergillus niger (CAA43130) & Pectin lyase & PL1 & $\mathrm{Y}$ & $\mathrm{N}$ & $\mathrm{Y}$ & $\mathrm{N}$ & CG \\
\hline 67 & Nectria haematococca (AAA33338) & Pectin lyase & PL3 & $\mathrm{Y}$ & $\mathrm{N}$ & $\mathrm{N}$ & $\mathrm{N}$ & $\mathrm{C}$ \\
\hline 68 & Aspergillus aculeatus (AAA64368) & Pectin lyase & PL4 & $\mathrm{Y}$ & $\mathrm{N}$ & $\mathrm{N}$ & $\mathrm{N}$ & $\mathrm{C}$ \\
\hline 69 & Aspergillus awamori (BAA13434) & Acetyl xylan esterase & CE1 & $\mathrm{Y}$ & $\mathrm{N}$ & $\mathrm{Y}$ & $\mathrm{N}$ & CG \\
\hline 70 & $\begin{array}{l}\text { Neocallimastix patriciarum } \\
\text { (AAB69091) }\end{array}$ & Acetyl xylan esterase & CE2 & $\mathrm{N}$ & $\mathrm{N}$ & $\mathrm{N}$ & $\mathrm{N}$ & None \\
\hline 71 & N. patriciarum (AAB69092) & Acetyl xylan esterase & CE3 & $\mathrm{Y}$ & $\mathrm{Y}$ & $\mathrm{N}$ & $\mathrm{N}$ & $\mathrm{CL}$ \\
\hline 72 & Glomerella lindemuthiana (AAT68493) & Chitin deacetylase & CE4 & $\mathrm{Y}$ & $\mathrm{Y}$ & $\mathrm{Y}$ & $\mathrm{Y}$ & All \\
\hline 73 & N. patriciarum (AAB69090) & Acetyl xylan esterase & CE6 & $\mathrm{N}$ & $\mathrm{N}$ & $\mathrm{N}$ & $\mathrm{N}$ & None \\
\hline 74 & C. carbonum (AF159252) & Pectin methylesterase (PME1) & CE8 & $\mathrm{N}$ & $\mathrm{Y}$ & $\mathrm{Y}$ & $\mathrm{N}$ & LG \\
\hline 75 & Candida albicans (AAF04335) & $\begin{array}{l}\text { N-Acetylglucosamine 6-phosphate } \\
\text { deacetylase }\end{array}$ & CE9 & $\mathrm{Y}$ & $\mathrm{N}$ & $\mathrm{Y}$ & $\mathrm{N}$ & CG \\
\hline \multirow[t]{2}{*}{76} & Aspergillus niger (CAC41360) & Rhamnogalacturonan acetyl esterase & CE12 & $\mathrm{Y}$ & $\mathrm{N}$ & $\mathrm{Y}$ & $\mathrm{N}$ & CG \\
\hline & Totals & & & 48 & 31 & 52 & 22 & \\
\hline
\end{tabular}




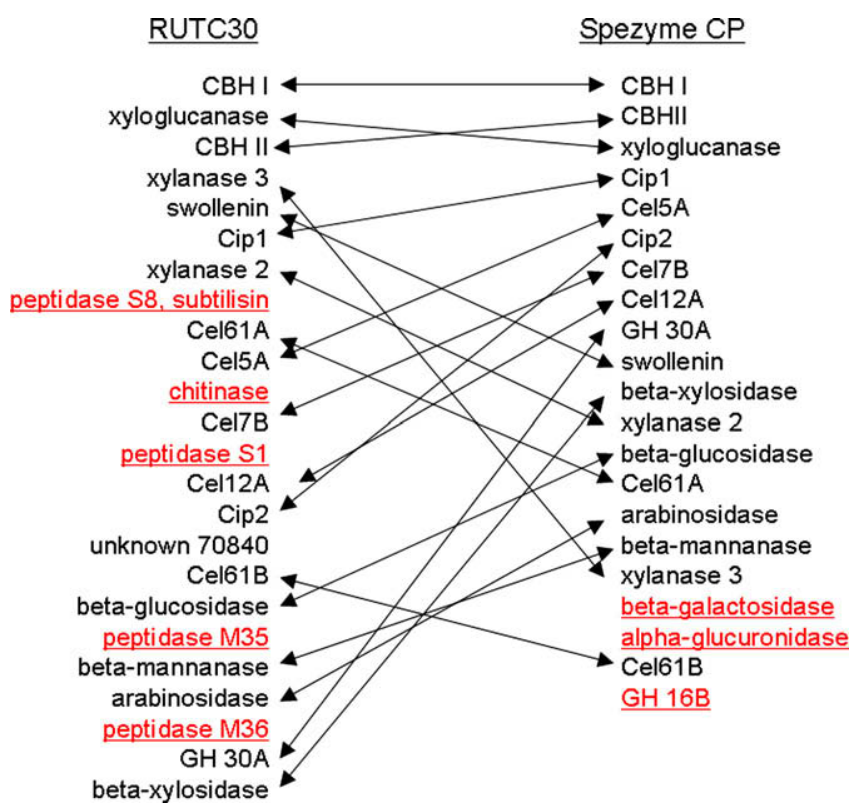

Fig. 1. Comparison of proteins found in the secretome of Trichoderma reesei RUTC30 grown on corn stover and Spezyme $\mathrm{CP}$. Proteins are ordered by relative abundance in RUTC30 based on total spectral counts. Arrows connect the same proteins. Proteins found in one but not the other are underlined in red. Only the most abundant proteins are shown (see Table 1). (For interpretation of the references to color in this figure legend, the reader is referred to the web version of this article.)

pyrosequencing and are therefore also composed of hundreds of thousands, randomly spaced, short reads, observation of a gene in G. marginata that is unobservable in A. bisporigera strengthens the case that the gene is truly absent from A. bisporigera.

Second, five housekeeping proteins were used to test whether the A. bisporigera and G. marginata partial genomic sequences adequately sample their respective genomes. Enolase, $\beta$-tubulin, glyceraldehyde-3-phosphate dehydrogenase, triose phosphate isomerase, and actin from $C$. cinerea were used as queries. All of the corresponding genes were represented by multiple clear, strong hits in both A. bisporigera and G. marginata (Supplementary Table S1). We have also searched these databases with many other highly conserved proteins and have never failed to find multiple hits (unpublished results). From this we conclude that 454 pyrosequencing appears to cover the genome without significant bias. This was also the conclusion of an early 454 case study of Neurospora crassa (www.454.com/downloads/454_CASE_STUDY_ genome_coverage.pdf).

The collection of $T$. reesei proteins (Table 1 ) was then used to search the genomes of C. cinerea, L. bicolor, G. marginata, and A. bisporigera. Proteins of completely unknown function (Table 1 ) were discarded as uninformative, although proteins of unknown function that could be assigned to a GH family were retained. A summary of the results are shown in Table 2 . The protein numbering between Tables 1 and 2 was retained for ease of comparison. Details including expect scores, bit scores, and percent identities are provided in Supplementary Table S2. The sequences with the best hits against each search query in A. bisporigera and G. marginata are given in Supplementary Figure S1.

Not all of the CAZy GH families examined in L. bicolor by Martin et al. (2008) are present in the $T$. reesei secretome. Therefore, in order to make the comparative analysis of $A$. bisporigera more robust, we added some additional proteins as queries (Table 2 ). These included representatives of GH43 ( $\beta$-xylosidase) and GH51 (arabinosidase), which are not present in the secretome of $T$. reesei (they are not in the genome, either), and GH45 (T. reesei endoglu- canase V). C. cinerea and G. marginata, but not the two ECM fungi, have representatives of GH43 and GH51 (Table 2). Of the four fungi, only G. marginata has GH45 (Table 2).

T. reesei appears to lack any polysaccharide lyases (PL), including pectin lyases. L. bicolor has no members of PL families 1, 3, 4, or 9 (Martin et al., 2008). Biochemically characterized representatives of PL families 1, 3, and 4 were used as queries (PL9 was omitted because there are only two fungal members of PL9 in CAZy, and neither is biochemically characterized). One PL (PL1) is present only in the two saprophytic fungi, and the other two PL's (PL3 and 4) have orthologs only in C. cinerea (Table 1 ).

Two other classes of enzymes were investigated in more detail. The first was GH family 28 , which contains fungal polygalacturonases (PG). PG's are the most extensively studied cell-wall-degrading enzymes from filamentous fungi, particularly from the point of view of their involvement in plant pathogenesis (Di Matteo et al., 2006). Many fungal PG's elicit strong plant defense responses, either directly or via the oligogalacturonide products that they release from pectins. Martin et al. (2008) reported that L. bicolor has six genes of GH family 28 . The presence of at least two GH28 members in L. bicolor was confirmed by our results using the T. reesei PG (protein 103049) as query (Table 2 and Supplementary Table S2). C. cinerea and G. marginata also have orthologs of the $T$. reesei $\mathrm{PG}$ (Table 1 ). However, we could not find any evidence of any PG gene in the genome of $A$. bisporigera (Table 2, Supplementary Table S2). To confirm that this negative result was not due to reliance on a single PG as query, we analyzed the genomes of the four basidiomycetes with two additional PGs, endoPG (PGN1) and exoPG (PGX1) from the ascomycete Cochliobolus carbonum. Both of these enzymes are biochemically characterized (ScottCraig et al., 1990, 1998). The results were the same as with the $T$. reesei PG, that is, at least one ortholog was found in C. cinerea, L. bicolor, and G. marginata, but none were found in A. bisporigera (Table 2 ). Furthermore, $A$. bisporigera does not contain orthologs of any of the six members of the putative (i.e., biochemically uncharacterized) PG family of the basidiomycete Chondrostereum purpureum (data not shown) (Williams et al., 2002).

The second class that was studied in more detail was the carbohydrate esterase (CE) family. This was done because of the observations that two characterized acetylxylan esterases of $T$. reesei (Axe1 and Axe2, both in CE family 5) are present in all of the fungi except A. bisporigera (Table 2), and Aes1 (CE16) and glucuronyl esterase (also known as Cip2; CE15) are absent in both A. bisporigera and $L$. bicolor. Therefore, ECM fungi, especially A. bisporigera, appear to be deficient in carbohydrate esterases. To examine this further, a biochemically characterized representative of each of the other classes of CE were used as TBLASTN queries against all four fungi. There are 16 families of CE in CAZy, but only CE's 1-4, $6,8,9$, and 12 contain any fungal members. The results support the conclusion that ECM fungi, especially $A$. bisporigera, are strongly deficient in CE's as well as GH's (Table 2).

T. reesei has 10-12 Carbohydrate Binding Modules (CBM) of family 1 based on BLASTP with the last 73 amino acids of CBHI from T. reesei. Martin et al. (2008) reported that $L$. bicolor has only one member of CBM family 1 . We were not able to find any clear evidence for any CBMs in $A$. bisporigera by TBLASTN when using CBM1 of $T$. reesei $\mathrm{CBHI}$ as query. In contrast, $G$. marginata has eight to twelve CBMs of family 1 , with expect scores ranging from $8.00 \mathrm{E}-10$ to $6.00 \mathrm{E}-04$ (data not shown). Therefore, at this level also, the ECM fungus $A$. bisporigera appears to be deficient in the capacity to interact with plant cell wall polysaccharides.

Collectively, our analysis indicates that $A$. bisporigera, like $L$. bicolor, is deficient in secreted enzymes that act on plant cell walls (Table 2). Orthologs of 18 of the 76 T. reesei proteins in Table 2 are present in the two saprophytic fungi but not the two ECM fungi. Of these, 11 are GH's, five are CE's, one is a PL, and one is a pep- 
tidase. Fifteen are present in all four fungi, eight are in none, and the others show different patterns of distribution. Of the total number of analyzed proteins, 48 and 52 are present in the two saprophytes, $C$. cinerea and $G$. marginata, respectively, whereas only 31 and 22 are present in the two ECM fungi, L. bicolor and A. bisporiger$a$, respectively. Based on presence or absence of carbohydrate-active families of $\mathrm{GH}, \mathrm{PL}$, and $\mathrm{CE}$, the two saprophytes have at least one member of 38 and 41 families, respectively, and the two ECM fungi have 22 and 18, respectively. In other words, at the family level the ECM fungi have $\sim 50 \%$ as many as the saprophytes.

If the analysis is restricted to GH's, 18 of the $35 \mathrm{GH}$ 's secreted by T. reesei (51\%), representing 25 families, have no orthologs in either of the two ECM fungi, as opposed to $30(86 \%)$ that are present in both of the two saprophytes. This might still underestimate the paucity of plant cell-wall-degrading enzymes in the ECM fungi, because some of the $\mathrm{GH}$ and $\mathrm{CE}$ enzymes of $T$. reesei are active on polysaccharides not found in plant cell walls, or might have functions other than supporting saprophytic growth on plant cell walls, such as remodeling fungal cell walls during growth and development. Such proteins include two GH18 proteins (encoding putative chitinases), $\beta 1,3$-glucanase (fungal but not plant cell walls contain large amounts of $\beta 1,3$-glucan), $\alpha$-trehalase, two $\beta$-glucosidases (a large family that has many different substrates), and chitin deacetylase. All of these are present in all four fungi, which is consistent with them having an endogenous role in fungal growth and development and not saprophytic growth. $\beta$-Mannanase and $\alpha$-mannosidase are also present in all four fungi, but because mannans and mannose are present in both plant and fungal cell walls, no conclusions can be deduced about their possible functions in either fungal growth or interaction with plants.

Of 10 peptidases in the $T$. reesei secretome, three have orthologs in all four fungi, three in none of the fungi, and the others have different patterns. An ortholog of one peptidase (81070) was present only in the two ECM fungi. Although plant cell walls contain structural and enzymatic proteins, secreted peptidases have many possible functions other than degradation of plant cell wall proteins (e.g., remodeling of fungal wall proteins or degradation of nonplant proteins). Therefore, it is not surprising that peptidases show no particular pattern of distribution among the four analyzed basidiomycetes.

Some encoding genes were found in only a single one of the four fungi. There were four genes specific to G. marginata (endo-galactanase, two arabinosidases, and endoglucanase $V$ ), four specific to C. cinerea (peptidase M35, GH30A, and two pectin lyases), and one specific to A. bisporigera (ribonuclease 70919). It is difficult to see any correlation between these proteins and the biology of the respective fungi.

\section{Discussion}

\subsection{Proteomics of $T$. reesei}

Proteomics has been used to evaluate the secreted proteins of a number of fungi grown in vitro and in vivo (Bouws et al., 2008; Paper et al., 2007). Despite its industrial importance, there have been few published proteomics studies of $T$. reesei (Vinzant et al., 2001; Bouws et al., 2008). With the completion of the genome sequence of $T$. reesei, it is now possible to obtain much more information from MS-based proteomics methods that do not rely on 2-D gels or orthology to proteins from other organisms (Martinez et al., 2008). Our results indicate that, as a conservative estimate, $T$. reesei secretes at least 80 proteins, many of which are biochemically and genetically characterized glycosyl hydrolases, peptidases, and carbohydrate esterases. Only one putative oxidoreductase was detected in the secretome of $T$. reesei, in contrast to some other fungi, such as $P$. chrysosporium, in which $13 \%$ of the secreted proteins are oxidoreductases such as lignin peroxidase (Vanden Wymelenberg et al., 2006).

A commercial "cellulase" preparation, Spezyme CP, known to be made by fermentation of $T$. reesei, is qualitatively similar to $T$. reesei RUTC30 grown on corn stover, except for the absence of multiple, abundant proteases in the commercial preparation. From this result, one can deduce that either the commercial strain of $T$. reesei used to make Spezyme CP has been engineered to delete or downregulate the protease genes, in order to enhance long term stability of the other enzymes, or that industrial growth conditions are adjusted to suppress protease production.

\subsection{Analysis of cell-wall-degrading enzymes in the ECM fungus A. bisporigera}

The validity of using a partial genome sequence to study the presence and absence of plant cell wall-active enzymes in the ECM fungus $A$. bisporigera is supported by comparison to G. margin$a t a$, for which a similar survey genome sequence is available, and by the demonstration that genes for multiple housekeeping proteins are detectable in the genome sequences.

The $T$. reesei proteins were used as a representative set of extracellular plant cell wall-active enzymes to analyze the genomic potential of the ECM fungus $A$. bisporigera to make the same kind of enzymes. Several factors legitimize this approach. First, $T$. reesei is one of the best, if not the best, characterized fungi from the point of view of the combined genetic and biochemical analysis of its secreted degradative proteins, particularly ones active on plant cell wall polysaccharides (Martinez et al., 2008). Second, T. reesei makes a large number of such enzymes, giving good representation of the biochemical breadth of the Kingdom Mycota. Third, the analysis was strengthened by adding proteins from $\mathrm{GH}, \mathrm{PL}$, and $\mathrm{CE}$ families not present in $T$. reesei, as well as by adding additional representatives of $\mathrm{GH} 28$. The resulting set of proteins used in the analysis is thus comparable in scope to that used by Martin et al. (2008).

\subsection{Comparison of A. bisporigera, L. bicolor, and other ECM fungi}

Our analysis of the genome of $A$. bisporigera supports the conclusion of Martin et al. (2008) in regard to L. bicolor that at least these two ECM fungi lack the genomic potential to biosynthesize many extracellular enzymes that are active on linkages found in plant cell walls. Furthermore, although many fungi have multiple representatives of many $\mathrm{GH}$ families (i.e., there is high genetic redundancy), even single representatives of many of the major groups of glycosyl hydrolases and carbohydrate esterases are absent from the genomes of either of these two fungi. Of particular note, both $L$. bicolor and A. bisporigera lack any apparent enzymes related to $\mathrm{CBHI}$ or $\mathrm{CBHII}$ (exocellobiohydrolases), which are central fungal enzymes in the degradation of cellulose.

A. bisporigera appears to be somewhat more deficient than $L$. bicolor in extracellular enzymes active on plant cell walls. For example, $L$. bicolor but not $A$. bisporigera has genes encoding enzymes in GH family 28 . In regard to carbohydrate esterases (CE's), whereas $L$. bicolor has genes encoding four CE families $(3,4,5,8)$, A. bisporigera has only one, CE4. Even this family is more likely to be involved in modification or degradation of fungal rather than plant walls because it contains chitin deacetylases.

$A$. bisporigera and $L$. bicolor are not completely devoid of extracellular degradative enzymes. Their genomes secrete multiple peptidases, as well as GH's in families 3, 5, 16, 18, 37, 47, 55, 61, 67, and 95 (Table 2; Martin et al., 2008). Of these, GH families 5, 18, 47 , and 55 contain $\beta$-mannanases, chitinases, $\alpha$-mannosidases, and $\beta 1,3$-glucanases, respectively, whose substrates are major components of fungal cell walls. Therefore, these might be in- 
volved in growth-related remodeling of the fungal cell wall or saprophytism on other fungi, and not in degradation of plant cell wall polymers. Family 37 contains $\alpha$-trehalases, which are not plant cell-wall-degrading enzymes. GH3 and GH16 are both large families containing enzymes that act on many different types of substrates. Therefore, of the GH's that are potentially made by ECM fungi, most could have functions other than degradation of plant cell wall polymers.

Based on our results and those of Martin et al. (2008), it appears that the presence or absence of a large complement of extracellular enzymes is not correlated with ability to grow saprophytically. $L$. bicolor grows readily in culture and forms fruiting bodies on a variety of mycological media (Kropp and Fortin, 1988), but A. bisporigera grows extremely slowly $(\sim 1 \mathrm{~cm} /$ month) and does not form fruiting bodies in culture. G. marginata, which does have many enzymes, grows only slightly better than $A$. bisporigera. Therefore, the presence or absence of high plant-wall-degrading potential appears to correlate better with ecological niche, namely, being ectomycorrhizal, than with ability to grow saprophytically.

There are two plausible hypotheses to explain the association between loss of enzymes and the ECM ecological niche. One is that ECM fungi have lost these genes because they are no longer needed, i.e., once ECM fungi evolved to obtain their reduced carbon from their hosts and not, like many other fungi, from nonliving plant debris, their extracellular degradative enzymes no longer contributed to their fitness and were thus eventually lost by mutation. The second hypothesis is that the genes have been lost because the enzymes are unfavorable to the symbiotic interaction. Extracellular enzymes that degrade plant cell wall polymers can be detrimental to plants either by causing direct damage to potential host plants, or by releasing elicitor-active oligosaccharide fragments that induce plant defenses, including the hypersensitive response, which results in plant cell death (Samac and Graham, 2007).

Considering that there are $>5000$ species of ECM fungi, it is possible that the pattern of enzymes observed in L. bicolor and A. bisporigera is not universally true for ECM fungi. Previous studies have detected cellulases, xylanases, and other plant cell-wall-degrading enzymes in other ECM fungi, including A. regalis (syn. A. muscaria var. umbrina), although apparently in no case have these observations been confirmed by identification of the responsible enzymes or genes (Cairney and Burke, 1994; Cao and Crawford, 1993; Colpaert and van Laere, 1996; Hutchison, 1990; Maijala et al., 1991; Terashita et al., 1995). L. bicolor and A. bisporigera may form one end of a continuum of saprophytic capacity among ECM fungi (Read and Perez-Moreno, 2003). Because many ECM fungi, including A. bisporigera, grow prohibitively slowly in culture, genomic analysis is the only way to analyze their potential for biosynthesizing secreted degradative enzymes. The present work illustrates the value of even a partial genomic sequence for addressing such questions.

The genera Coprinopsis, Laccaria, and Galerina are all in the Agaricoid clade of the Agaricales, whereas Amanita is in the Pluteoid clade. There are at least 11 independent origins of the ECM habit in the Euagarics (Matheny et al., 2006), and this trait appears to have evolved independently in Amanita and Laccaria. Loss of cellwall-degrading enzymes has therefore also evolved independently more than once.

\section{Acknowledgments}

We thank Curtis Wilkerson, Doug Whitten, Kevin Carr, Shari Tjugum-Holland, and Jeff Landgraf of the MSU Research Technology Support Facility for the proteomics analysis, 454 sequencing, and assembly. This work was supported by the US Department of Energy, Energy Biosciences Program, the DOE Great Lakes Bioenergy Research Center, and an MSU Strategic Partnership Grant.

\section{Appendix A. Supplementary material}

Supplementary data associated with this article can be found, in the online version, at doi:10.1016/j.fgb.2009.02.001.

\section{References}

Baldrian, P., Gabriel, J., 2003. Lignocellulose degradation by Pleurotus ostreatus in the presence of cadmium. FEMS Microbiol. Lett. 220, 235-240.

Beliën, T., Van Campenhout, S., Robben, J., Volckaert, G., 2006. Microbial endoxylanases: effective weapons to breach the plant cell-wall barrier or, rather, triggers of plant defense systems? Mol. Plant Microbe Interact. 19, 10721081.

Bouws, H., Watatenberg, A., Zorn, H., 2008. Fungal secretomes - nature's toolbox for white biotechnology. Appl. Microbiol. Biotechnol. 80, 381-388.

Cairney, J.W.G., Burke, R.M., 1994. Fungal enzymes degrading plant cell walls: their possible significance in the ectomycorrhizal symbiosis. Mycol. Res. 98, 13451346.

Cantarel, B.L., Coutinho, P.M., Rancurel, C., Bernard, T., Lombard, V., Henrissat, B., in press. The carbohydrate-active enzymes database (CAZy): an expert resource for glycogenomics. Nucleic Acids Res.

Cao, W., Crawford, D.L., 1993. Carbon nutrition and hydrolytic and cellulolytic activities in the ectomycorrhizal fungus Pisolithus tinctorius. Can. J. Microbiol 39, 529-535.

Chen, H., Wilkerson, C.G., Kuchar, J.A., Phinney, B.S., Howe, G.A., 2005. Jasmonateinducible plant enzymes degrade essential amino acids in the herbivore midgut. Proc. Natl. Acad. Sci. USA 102, 19237-19242.

Colpaert, J.V., van Laere, K.K., 1996. Decomposition, nitrogen and phosphorus mineralization from beech leaf litter colonized by ectomycorrhizal or litterdecomposing basidiomycetes. New Phytol. 134, 123-132.

Colpaert, J.V., van Tichelin, K.K., 1996. Decomposition, nitrogen and phosphorus mineralization from beech leaf litter colonized by ectomycorrhizal or litterdecomposing basidiomycetes. New Phytol. 134, 123-132.

Craig, R., Beavis, R.C., 2003. A method for reducing the time required to match protein sequences with tandem mass spectra. Rapid Commun. Mass Spectrom. $17,2310-2316$

Cuomo, C.A., Güldener, U., Xu, J.R., Trail, F., Turgeon, B.G., Di Pietro, A., Walton, J.D. Ma, L.J., Baker, S.E., Rep, M., et al., 2007. The Fusarium graminearum genome reveals a link between localized polymorphism and pathogen specialization. Science 317, 1400-1402.

Davis, E.E., Jong, S.C., 1976. Basidiocarp formation by Laccaria laccata in agar culture. Mycologia 68, 211-214.

Dean, R.A., Talbot, N.J., Ebbole, D.J., Farman, M.L., Mitchell, T.K., Orbach, M.J., et al., 2005. The genome sequence of the rice blast fungus Magnaporthe grisea. Nature 434, 980-986.

Di Matteo, A., Bonivento, D., Tsernoglou, D., Federici, L., Cervone, F., 2006 Polygalacturonase-inhibiting protein (PGIP) in plant defence: a structural view. Phytochemistry 67, 528-533.

Ding, S., Ge, W., Buswell, J.A., 2006. Cloning of multiple cellulase cDNAs from Volvariella volvacea and their differential expression during substrate colonization and fruiting. FEMS Microbiol. Lett. 263, 207-213.

D’Ovidio, R., Mattei, B., Roberti, S., Bellincampi, D., 2004. Polygalacturonases, polygalacturonase-inhibiting proteins and pectic oligomers in plant-pathogen interactions. Biochim. Biophys. Acta 1696, 237-244.

Enkerli, J., Felix, G., Boller, T., 1999. The enzymatic activity of fungal xylanase is not necessary for its elicitor activity. Plant Physiol. 121, 391-397.

Fekete, E., Seiboth, B., Kubicek, C.P., Szentirmai, A., Karaffa, L., 2008. Lack of aldose 1epimerase in Hypocrea jecorina (anamorph Trichoderma reesei): a key to cellulase gene expression on lactose. Proc. Natl. Acad. Sci. USA 105, 7141-7146.

Gulden, G., Dunham, S., Stockman, J., 2001. DNA studies in the Galerina marginata complex. Mycol. Res. 105, 432-440.

Hallen, H.E., Luo, H., Scott-Craig, J.S., Walton, J.D., 2007. Gene family encoding the major toxins of lethal Amanita mushrooms. Proc. Natl. Acad. Sci. USA 104 19097-19101.

Henrissat, B., Davies, G.J., 1997. Structural and sequence-based classification of glycoside hydrolases. Curr. Opin. Struct. Biol. 7, 637-644.

Hutchison, L.J., 1990. Studies on the systematics of ectomycorrhizal fungi in axenic culture. II. The enzymatic degradation of selected carbon and nitrogen compounds. Can. J. Bot. 68, 1522-1530.

Kersten, P., Cullen, D., 2007. Extracellular oxidative systems of the lignin-degrading basidiomycete Phanerochaete chrysosporium. Fungal Genet. Biol. 44, 77-87.

Kropp, B.R., Fortin, J.A., 1988. The incompatibility system and relative ectomycorrhizal performance of monokaryons and reconstituted dikaryons of Laccaria bicolor. Can. J. Bot. 66, 289-294.

Kusuda, M., Ueda, M., Mihatake, K., Terashita, T., 2008. Characterization of the carbohydrase productions of an ectomycorrhizal fungus, Tricholoma matsutake. Mycoscience 49, 291-297.

Lionetti, V., Raiola, A., Camardella, L., Giovane, A., Obel, N., Pauly, M., Favaron, F. Cervone, F., Bellincampi, D., 2007. Overexpression of pectin methylesterase inhibitors in arabidopsis restricts fungal infection by Botrytis cinerea. Plant Physiol. 143, 1871-1880.

Maijala, P., Fagerstedt, K.V., Raudaskoski, M., 1991. Detection of extracellular cellulolytic and proteolytic activity in ectomycorrhizal fungi and Heterobasidion annosum (Fr.) Bref. New Phytol. 117, 643-648. 
Martin, F., Aerts, A., Ahren, D., Brun, A., Danchin, E.G.J., Duchaussoy, F., Gibon, J. et al., 2008. The genome of Laccaria bicolor provides insights into mycorrhizal symbiosis. Nature 452, 88-93.

Martinez, D., Berka, R.M., Henrissat, B., Saloheimo, M., Arvas, M., Baker, S.E. Chapman, J., et al., 2008. Genome sequencing and analysis of the biomassdegrading fungus Trichoderma reesei (syn. Hypocrea jecorina). Nat. Biotechnol. 26, 553-560.

Matheny, P.B., Curtis, J.M., Hofstetter, V., Aime, M.C., Moncalvo, J.-M., et al., 2006. Major clades of Agaricales: a multilocus phylogenetic overview. Mycologia 98, 982-995.

Merino, S.T., Cherry, J., 2007. Progress and challenges in enzyme development for biomass utilization. Adv. Biochem. Eng./Biotechnol 108, 95-120.

Nesvizhskii, A.I., Keller, A., Kolker, E., Aebersold, R., 2003. A statistical model for identifying proteins by tandem mass spectrometry. Anal. Chem. 75, 46464658.

Paper, J.M., Scott-Craig, J.S., Adhikari, N.D., Cuomo, C.A., Walton, J.D., 2007. Comparative proteomics of extracellular proteins in vitro and in planta from the pathogenic fungus Fusarium graminearum. Proteomics 7, 3171-3183.

Read, D.J., Perez-Moreno, J., 2003. Mycorrhizas and nutrient cycling in ecosystems a journey towards relevance? New Phytol. 157, 475-492.

Samac, D.A., Graham, M.A., 2007. Recent advances in legume-microbe interactions: recognition, defense response, and symbiosis from a genomic perspective. Plant Physiol. 144, 582-587.

Scott-Craig, J.S., Panaccione, D.G., Cervone, F., Walton, J.D., 1990 Endopolygalacturonase is not required for pathogenicity of Cochliobolus carbonum on maize. Plant Cell 2, 1191-1200.

Scott-Craig, J.S., Cheng, Y.Q., Cervone, F., De Lorenzo, G., Pitkin, J.W., Walton, J.D., 1998. Targeted mutants of Cochliobolus carbonum lacking the two major extracellular polygalacturonases. Appl. Environ. Microbiol. 64, 14971503.
Smith, P.K., Krohn, R.I., Hermanson, G.T., Mallia, A.K., Gartner, F.H., Provenzano, M.D., Fujimoto, E.K., Goeke, N.M., Olson, B.J., Klenk, D.C., 1985. Measurement of protein using bicinchoninic acid. Anal. Biochem. 150, 76-85.

Stricker, A.R., Mach, R.L., de Graaff, L.H., 2008. Regulation of transcription of cellulases- and hemicellulases-encoding genes in Aspergillus niger and Hypocrea jecorina (Trichoderma reesei). Appl. Microbiol. Biotechnol. 78, 211-220.

ten Have, A., Mulder, W., Visser, J., van Kan, J.A.L., 1998. The endopolygalacturonase gene Bcpg1 is required for full virulence of Botrytis cinerea. Mol. Plant Microbe Interact. 11, 1009-1016.

Terashita, T., Kono, M., Yoshikawa, K., Shishiyama, J., 1995. Productivity of hydrolytic enzymes by mycorrhizal mushrooms. Mycoscience 36, 221-225.

Teymouri, F., Laureano-Perez, L., Alizadeh, H., Dale, B.E., 2005. Optimization of the ammonia fiber explosion (AFEX) treatment parameters for enzymatic hydrolysis of corn stover. Bioresour. Technol. 96, 2014-2018.

Vanden Wymelenberg, A., Minges, P., Sabat, G., Martinez, D., Aerts, A., Salamov, A., Grigoriev, I., Shapiro, H., Putnam, N., Belinky, P., Dosoretz, C., Gaskell, J., Kersten, P., Cullen, D., 2006. Computational analysis of the Phanerochaete chrysosporium v2.0 genome database and mass spectrometry identification of peptides in ligninolytic cultures reveal complex mixtures of secreted proteins. Fungal Genet. Biol. 43, 343-356.

Vinzant, T.B., Adney, W.S., Decker, S.R., Baker, J.O., Kinter, M.T., Sherman, N.E., Fox, J.W., Himmel, M.E., 2001. Fingerprinting Trichoderma reesei hydrolases in a commercial cellulase preparation. Appl. Biochem. Biotech. 91, 99-107.

Walton, J.D., 1994. Deconstructing the cell wall. Plant Physiol. 104, 1113-1118.

Williams, H.L., Tang, Y., Hintz, W.E., 2002. Endopolygalacturonase is encoded by a multigene family in the basidiomycete Chondrostereum purpureum. Fungal Genet. Biol. 36, 71-83.

Zhang, P., Chen, Z.H., Hu, J.S., Wei, B.Y., Zhang, Z.G., Hu, W.Q., 2005. Production and characterization of amanitin toxins from a pure culture of Amanita exitialis. FEMS Microbiol. Lett. 252, 223-228. 